\title{
High performance of low cost soft magnetic materials
}

\author{
JOSEFINA M SILVEYRA*, EMÍLIA ILLEKOVÁ ${ }^{\dagger}$ MARCO COÏSSON ${ }^{\dagger \dagger}$, \\ FEDERICA CELEGATO ${ }^{\dagger \dagger}$, FRANCO VINAI ${ }^{\dagger \dagger}$, PAOLA TIBERTO ${ }^{\dagger \dagger}$, JAVIER A MOYA and \\ VICTORIA J CREMASCHI \\ Lab. de Sólidos Amorfos, INTECIN, FIUBA-CONICET, Paseo Colón 850, (C1063ACV) Buenos Aires, Argentina \\ ${ }^{\dagger}$ Institute of Physics SAS, Dúbravská cesta 9, 84511 Bratislava, Slovak Republic \\ ${ }^{\dagger \dagger}$ Istituto Nazionale di Ricerca Metrologica, Strada delle Cacce 91, I-10135 Torino, Italy
}

MS received 17 May 2010

\begin{abstract}
The consistent interest in supporting research and development of magnetic materials during the last century is revealed in their steadily increasing market. In this work, the soft magnetic nanocrystalline FINEMET alloy was prepared with commercial purity raw materials and compared for the first time with the generally studied high purity one. The exhaustive characterization covers several diverse techniques: $X$-ray diffraction, Mössbauer spectroscopy, differential scanning calorimetry, differential thermal analysis and magnetic properties. In addition, a brief economic analysis is presented. For the alloys annealed at $813 \mathrm{~K}$, the value of the grain size was $16 \mathrm{~nm}$ with $19.5 \%$ of $\mathrm{Si}$, the coercivity was $0.30 \mathrm{~A} \mathrm{~m}^{-1}$ while the saturation was $1.2 \mathrm{~T}$. These results prove that structural, magnetic and thermal properties of this material are very close to the expensive high purity FINEMET alloy, while a cost reduction of almost $98 \%$ seems highly attractive for laboratories and industry. The analysis should be useful not only for the production of FINEMETs, but for other type of systems with similar constitutive elements as well, including soft and hard magnetic materials.
\end{abstract}

Keywords. Soft magnetic materials; FINEMET; raw materials; product technology; structural and magnetic properties.

\section{Introduction}

Magnetic materials have become an essential part of everyday life over the past century. They play an important role in diverse applications areas such as automotives, telecommunications, data storage, medical applications, military, aerospace and electric energy industry, including the generation, transmission and distribution. The production, trade and utilization of soft (easy to magnetize and demagnetize) and hard (hard to magnetize and demagnetize) magnetic materials generate a steadily growing market which is forecast to reach $\$ 28.5$ billion by 2012. Nations around the world have shown consistent interest in supporting research and development of magnetic materials.

Following this trend, in 1988 Yoshizawa developed a new soft magnetic material called FINEMET $\left(\mathrm{Fe}_{73.5} \mathrm{Si}_{13}\right.$ $\mathrm{Nb}_{3} \mathrm{~B}_{9} \mathrm{Cu}_{1}$ ) (Yoshizawa et al 1988). Since then, there have been numerous basic and applied studies on this type of nanocrystalline alloys, i.e. crystals $10-20 \mathrm{~nm}$ in size embedded in an amorphous matrix (Herzer 1990, 1997; Rixecker et al 1992; Crisan et al 2003; Muraca et al 2009; Silveyra et al 2009). These Fe-based alloys

\footnotetext{
*Author for correspondence (jsilveyra@fi.uba.ar)
}

exhibit excellent soft magnetic behaviour: high saturation magnetization $\left(M_{\mathrm{S}}>1 \mathrm{~T}\right)$, low coercivity $\left(H_{\mathrm{C}} \leq 1 \mathrm{~A} \mathrm{~m}^{-1}\right)$ and high relative magnetic permeability $\left(\mu_{\mathrm{r}(1 \mathrm{kHz})} \geq 10^{4}\right)$. Such properties make them suitable for a wide variety of technological applications such as transformer cores, inductive devices, magnetic shielding, sensors, etc (Herzer et al 2005). Other well known alloy systems in the nanocrystalline magnetic materials family are NANOPERM $(\mathrm{FeZrB}(\mathrm{Cu}))$ and HITPERM $(\mathrm{Fe}-$ $\mathrm{CoZrB}(\mathrm{Cu}))$.

Although more than two decades have passed since the development of FINEMET, several hundreds of articles have been published in the last few years revealing the still present interest in this family of materials from both research and industrial fields. In general, high purity elements (>99.99\%) have been used to prepare the alloy (Ayers et al 1997; Tamoria et al 2001; Kim et al 2004; Herzer et al 2005; Choi et al 2007; Prabhu et al 2007; Muraca et al 2009). In this work, FINEMET ribbons with commercial purity raw materials were produced, characterized and compared, by means of a wide variety of techniques, with high purity FINEMET for the first time. Our goal was to find out if their properties were comparable to the ones of the high purity alloy in order to reduce costs in laboratories and industry. The analysis should be useful not only for the production of FINEMETs, but for 
Table 1. Compositions of raw materials and FinCom alloy in atomic percentage.

\begin{tabular}{|c|c|c|c|c|c|c|}
\hline & $\mathrm{FeSi}$ & $\mathrm{FeNb}$ & $\mathrm{FeB}$ & $\mathrm{FeC}$ & $\mathrm{Cu}$ & FinCom \\
\hline B & & & $18 \cdot 00$ & & & $8 \cdot 63$ \\
\hline $\mathrm{Cu}$ & & & & & $99 \cdot 97$ & $0 \cdot 96$ \\
\hline $\mathrm{Fe}$ & 24.098 & $28 \cdot 70$ & $79 \cdot 34$ & $99 \cdot 25$ & & $73 \cdot 46$ \\
\hline $\mathrm{Nb}$ & & $68 \cdot 30$ & & & & $2 \cdot 89$ \\
\hline $\mathrm{Si}$ & $74 \cdot 220$ & 1.75 & $2 \cdot 00$ & $0 \cdot 14$ & & $12 \cdot 99$ \\
\hline Total elements & $98 \cdot 318$ & $98 \cdot 75$ & $99 \cdot 34$ & $99 \cdot 39$ & 99.97 & $98 \cdot 93$ \\
\hline $\mathrm{Al}$ & 0.630 & $1 \cdot 13$ & 0.05 & & & $0 \cdot 28$ \\
\hline $\mathrm{C}$ & $0 \cdot 140$ & $0 \cdot 12$ & $0 \cdot 50$ & $0 \cdot 1$ & & $0 \cdot 31$ \\
\hline $\mathrm{Ca}$ & $0 \cdot 840$ & & & & & $0 \cdot 10$ \\
\hline $\mathrm{Mn}$ & & & & 0.45 & & $0 \cdot 29$ \\
\hline $\mathrm{P}$ & $0 \cdot 043$ & & $0 \cdot 10$ & 0.03 & & $0 \cdot 06$ \\
\hline S & 0.029 & & 0.01 & 0.03 & & 0.04 \\
\hline Unknown & & & & & 0.03 & $0 \cdot 00$ \\
\hline Total impurities & $1 \cdot 682$ & $1 \cdot 25$ & 0.66 & 0.61 & 0.03 & 1.07 \\
\hline Total & $100 \cdot 000$ & $100 \cdot 00$ & $100 \cdot 00$ & $100 \cdot 00$ & $100 \cdot 00$ & $100 \cdot 00$ \\
\hline
\end{tabular}

other types of systems with similar constitutive elements as well, such as FeSiB alloys, NANOPERMs, HITPERMs (soft magnetic materials) and NdFeB (hard magnetic material).

\section{Experimental}

Master alloy ingots were prepared by melting commercial purity raw materials in argon atmosphere. The composition of raw elements and compounds can be seen in table 1. The mass of all raw materials needed to obtain an alloy as close as possible to pure FINEMET was calculated by using the simplex method: 9.4 wt. $\%$ of $\mathrm{FeSi}, 10.5$ wt.\% of $\mathrm{FeNb}, 8.0$ wt.\% of $\mathrm{FeB}, 70.9$ wt. $\%$ of $\mathrm{FeC}$ and 1.2 wt. $\%$ of $\mathrm{Cu}$. The resulting composition is called from now on as FinCom, was $\mathrm{Fe}_{73.5} \mathrm{Si}_{13} \mathrm{Nb}_{3} \mathrm{~B}_{8.5} \mathrm{Cu}_{1} \mathrm{X}_{1}$ (X= impurities: $\mathrm{Al}, \mathrm{C}, \mathrm{Ca}, \mathrm{Mn}, \mathrm{P}$ and $\mathrm{S}$ ) and it is also detailed in table 1 .

The ribbons were obtained from the ingots using the single wheel melt spinning technique in air atmosphere. Then, they were isothermally annealed for $1 \mathrm{~h}$ in vacuum $\left(10^{5} \mathrm{mbar}\right)$ in an electric resistance furnace at different temperatures: 573, 675, 723, 773, 813 and $873 \mathrm{~K}$.

Structural properties of the as-prepared and heat treated ribbons were studied by X-ray diffraction (XRD) and Mössbauer spectroscopy (MS). XRD measurements were performed at room temperature using a Rigaku Geiger Flex D-Max II TC diffractometer with a graphite monochromator, $\mathrm{CuK} \alpha$ radiation $(\lambda=1.5418 \AA)$ and $\mathrm{Ni}$ filter $(40 \mathrm{kV}, 20 \mathrm{~mA})$. From XRD patterns, different phases present in the alloy were determined and the lattice parameters of the crystalline phases were calculated. The crystals grain size was also estimated from XRD patterns $( \pm 1 \mathrm{~nm})$, since experience had shown that the values obtained through XRD were in agreement with other techniques, as for instance transmission electron microscopy (Crisan et al 2003). MS was carried out at room tempera- ture in transmission geometry using a constant acceleration drive and a ${ }^{57} \mathrm{Co}$ in $\mathrm{Rh}$ source. The calibration was done with an $\alpha$-Fe foil and isomer shifts (IS) are given relative to $\alpha$-Fe. The spectra were fitted using the NORMOS SITE programme (Brand 1987). Fe fractions in amorphous and crystalline phases for the ribbons annealed at $813 \mathrm{~K}$ were estimated from MS spectra.

The continuous heating crystallization measurements were performed in a Perkin Elmer DSC7 and a Perkin Elmer DTA7 in argon atmosphere. For DSC, heating rates $(\beta)$ of 10 and $40 \mathrm{~K} \mathrm{~min}^{-1}$ from 300 to $923 \mathrm{~K}$ were used. The as-quenched samples were cut into small pieces and $\sim 10 \mathrm{mg}$ were placed in platinum sample pans. Indium and zinc standards were used to calibrate the temperature (error less than $\pm 0.05 \%$ ) and the enthalpy (error less than $\pm 2 \%$ ). In the case of DTA, $\beta$ was $10 \mathrm{~K} \mathrm{~min}^{-1}$ and the temperature ranged from 300 to $1673 \mathrm{~K}$. The sample $(\sim 20 \mathrm{mg})$ was placed in an alumina pan. The standards used to calibrate the temperature (error less than $\pm 0.1 \%$ ) and the enthalpy (error less than $\pm 4 \%$ ) in the DTA instrument were aluminium and gold. In the case of DSC, the method of subtracting the first and the subsequently second heating run was always used.

Magnetic properties were characterized by the traditional fluxmetric method, obtaining $H_{\mathrm{C}}$ and $\mu_{0} M_{\mathrm{S}}$ from the hysteresis loops. The loops were measured by applying a low frequency longitudinal magnetic field on the sample and collecting the signal with a compensated secondary coil. Maximum fields of $740 \mathrm{~A} \mathrm{~m}^{-1}$ and $18.000 \mathrm{~A} \mathrm{~m}^{-1}$ were used to determine the $H_{\mathrm{C}}$ and $\mu_{0} M_{\mathrm{S}}$, respectively. A vibrating sample magnetometer (VSM) was also employed to measure hysteresis loops by applying longitudinal or transversal magnetic field on the ribbon plane. From these data, saturation (mass) magnetization $\left(\sigma_{\mathrm{S}}\right)$ was obtained and compared to the $\mu_{0} M_{\mathrm{S}}$ measured with the fluxmetric method. 
Table 2. Parameters obtained from Mössbauer spectrum fitting.

\begin{tabular}{|c|c|c|c|c|c|}
\hline Subspectrum & $\begin{array}{c}\text { Relative area between } \\
\text { peaks } 2 \text { and } 3 \text { (D23) }\end{array}$ & $\begin{array}{l}\text { Isomer shift (IS) } \\
\qquad\left(\mathrm{mm} \mathrm{s}^{-1}\right)\end{array}$ & $\begin{array}{l}\text { Quadrupolar splitting } \\
\text { (QS) }\left(\mathrm{mm} \mathrm{s}^{-1}\right)\end{array}$ & $\begin{array}{l}\text { Hyperfine magnetic } \\
\text { field }(\mathrm{BHF})(\mathrm{T})\end{array}$ & Area $(\%)$ \\
\hline S1 & $3 \cdot 1$ & $0 \cdot 04$ & $0 \cdot 00$ & $32 \cdot 8$ & $5 \cdot 6$ \\
\hline $\mathrm{S} 2$ & $3 \cdot 1$ & $0 \cdot 06$ & 0.04 & $31 \cdot 4$ & $12 \cdot 8$ \\
\hline S3 & $3 \cdot 1$ & $0 \cdot 12$ & 0.00 & $29 \cdot 2$ & $8 \cdot 0$ \\
\hline $\mathrm{S} 4$ & $3 \cdot 1$ & $0 \cdot 00$ & $0 \cdot 07$ & $27 \cdot 7$ & $3 \cdot 7$ \\
\hline S5 & $3 \cdot 1$ & $0 \cdot 19$ & $0 \cdot 00$ & $24 \cdot 7$ & $16 \cdot 9$ \\
\hline S6 & $3 \cdot 1$ & $0 \cdot 27$ & $0 \cdot 01$ & $19 \cdot 7$ & $13 \cdot 4$ \\
\hline Am 1 & - & $0 \cdot 14$ & 0.02 & $18 \cdot 4$ & $37 \cdot 4$ \\
\hline Am 2 & - & $0 \cdot 09$ & $0 \cdot 02$ & $4 \cdot 5$ & $2 \cdot 2$ \\
\hline
\end{tabular}

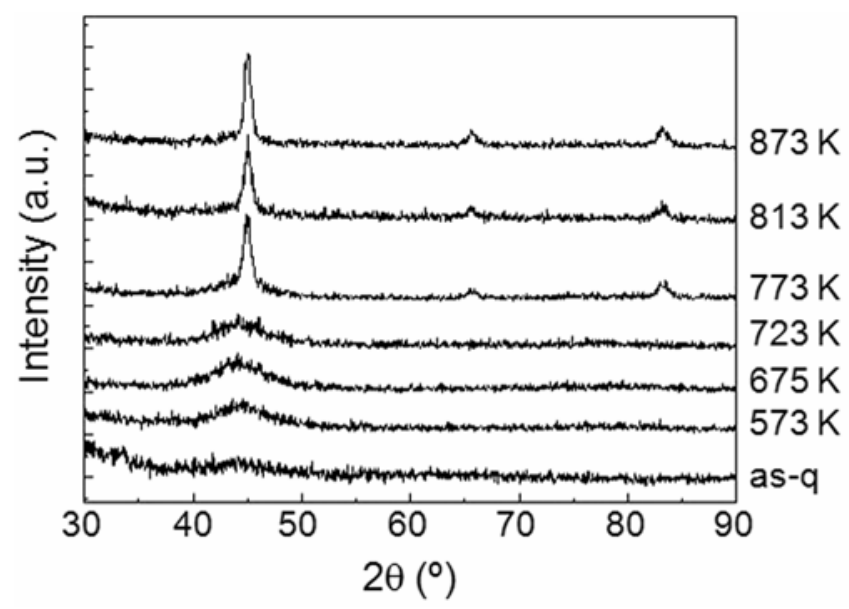

Figure 1. Diffractograms and crystallographic planes of ribbons in as-quenched state and after $1 \mathrm{~h}$ heat treatment at different temperatures: 573, 675, 723, 773, 813 and $873 \mathrm{~K}$.

\section{Results and discussion}

\section{$3.1 X$-ray diffraction}

In X-ray difractograms (figure 1), the nanocrystallization of FeSi phase was observed at $773 \mathrm{~K}$. The XRD peaks may correspond either to the crystalline structure $b c c$ or to DO3 (space group Fm3m). DO3 was assumed to be the correct structure as it was reported in the past for this alloy subjected to the same heat treatment (Rixecker et al 1993). The DO3 structure has other small characteristic peaks which were not observed probably because of the low peak-to-background ratio. Precipitation of borides was not detected even in the samples annealed at $873 \mathrm{~K}$.

From the diffractogram peak angles (figure 1), Bragg's law and knowing the crystalline phase structure, i.e. cubic, it was possible to calculate the nanocrystalline lattice parameter of the sample annealed at $813 \mathrm{~K}$ for $1 \mathrm{~h}$. These annealing conditions have shown to lead to the best soft magnetic properties for FINEMET (Yoshizawa et al 1988). While 5.680 $\pm 0.005 \AA$ was the lattice parameter for pure FINEMET (Crisan et al 2003), a value of $5 \cdot 676 \pm 0 \cdot 001 \AA$ was now calculated for FinCom.

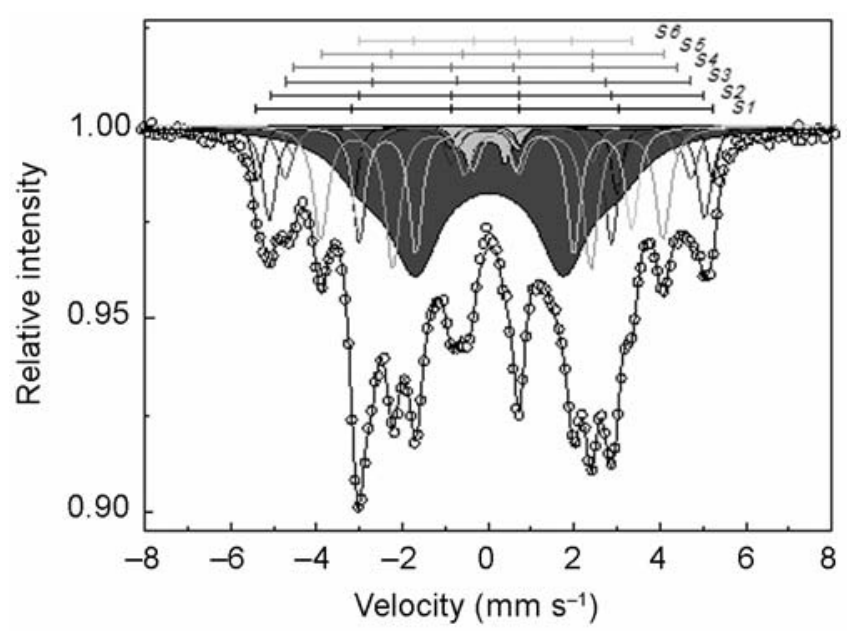

Figure 2. Mössbauer spectrum and fitting for FinCom annealed for $1 \mathrm{~h}$ at $813 \mathrm{~K}$. Shaded subspectra represent amorphous phases (dark grey: Am 1, light grey: Am 2), while the lines (S1-S6) correspond to crystalline phases.

The full width half maxima (FWHM) of the [ $\left.\begin{array}{lll}1 & 1 & 0\end{array}\right]$ diffraction peaks were estimated by Voigt curve fitting. After subtracting the instrumental line broadening, which was estimated using Fe standard, the grain size was estimated by applying the Scherrer equation (Klung and Alexander 1954). Pure FINEMET annealed at $813 \mathrm{~K}$ presented 10-20 nm grain size (Herzer 1997), whereas for FinCom we estimated 15, 16 and $17 \mathrm{~nm}$ grain sizes for 773,813 and $873 \mathrm{~K}$ heat treatments, respectively.

\subsection{Mössbauer spectroscopy}

Mössbauer spectrum for FinCom annealed at $813 \mathrm{~K}$ and its fitting results are shown in figure 2 and table 2. Two sextets were used for fitting the amorphous phase: a wide one called Am1 (line width, $\Gamma=1.5 \mathrm{~mm} \mathrm{~s}^{-1}$, hyperfine magnetic field, $\mathrm{BHF}=18.4 \mathrm{~T}$ ) and a narrow one called Am2 $\left(\Gamma=0.25 \mathrm{~mm} \mathrm{~s}^{-1}, \mathrm{BHF}=4.5 \mathrm{~T}\right)$. Both are represented in figure 2 by shaded subspectra. The six subspectra (S1-S6) corresponding to the crystalline phases were associated with different $\mathrm{Fe}$ sites in the non stoichio- 
metric DO3 structure (Rixecker et al 1993). They are plotted in different grey shades (figure 2).

Fe content in the amorphous phase was $39.6 \%$. The probability of occurrence of each kind of Fe environment can be calculated using a binomial distribution (Rixecker et al 1993) and depends on the $\mathrm{Si}$ content. Then, nanocrystals composition was determined to be $\sim 19.5 \%$ $\mathrm{Si}(\sim 80 \cdot 5 \% \mathrm{Fe})$. As can be seen in figure 3, the spectrum obtained for FinCom was very similar to pure FINEMET (Moya et al 2007). Hyperfine parameters and grain Si content were in good agreement with those reported by Rixecker et al (1992).

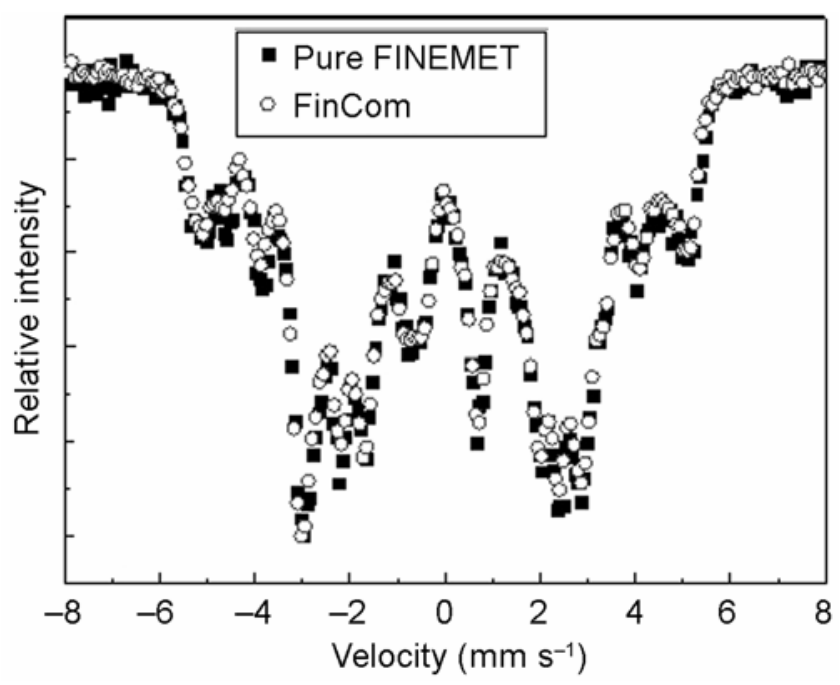

Figure 3. Comparison between annealed at $813 \mathrm{~K}$ FinCom and FINEMET (Moya et al 2007) Mössbauer spectra.

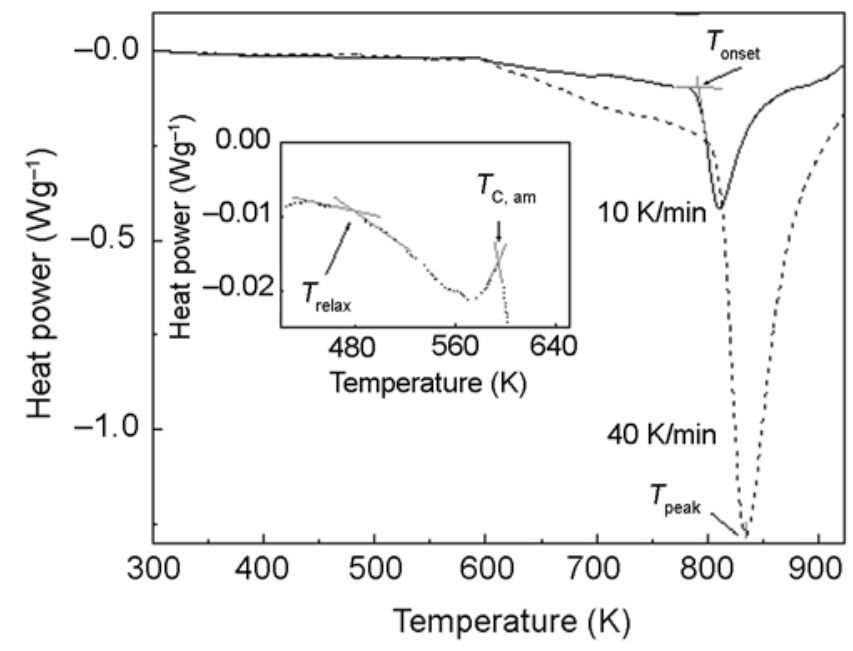

Figure 4. DSC curves of as-quenched FinCom at 10 and $40 \mathrm{~K} \mathrm{~min}^{-1}$ ( $T_{\text {onset }}$ : onset temperature, $T_{\text {peak }}$ : peak temperature). Inset: an expanded view of the lower temperature region at $40 \mathrm{~K} \mathrm{~min}^{-1}\left(T_{\text {relax }}\right.$ : relaxation temperature, $T_{\mathrm{C} \text {,am }}$ : amorphous Curie temperature).

\subsection{Thermal analyses}

From the DSC signal (figure 4), temperature parameters were obtained: relaxation temperature $\left(T_{\text {relax }}\right)$, amorphous Curie temperature $\left(T_{\mathrm{C}, \mathrm{am}}\right)$ and the ones corresponding to the first crystallization (R1), i.e. DO3 phase: onset temperature $\left(T_{\text {onset }}\right)$ and peak temperature $\left(T_{\text {peak }}\right) . T_{\text {relax }}$ was taken from the scan at $40 \mathrm{~K} \mathrm{~min}^{-1}$ for being the most reproducible. $T_{\mathrm{C}, \mathrm{am}}$ was slightly higher at $10 \mathrm{~K} \mathrm{~min}^{-1}$ because of the greater structural relaxation experienced. Also the enthalpy $(\Delta H)$ of the DO3 phase crystallization was calculated from the scan at $10 \mathrm{~K} \mathrm{~min}^{-1}$ because in the case of $40 \mathrm{~K} \mathrm{~min}^{-1}$ this transformation was not completed within the first measuring run. This quantity reflects the amount of the formed nanocrystalline phase which is responsible for the majority of the excellent magnetic properties of FINEMET. All the parameters are summarized in table 3 .

From DTA curves it was possible to study higher temperature transformations (figure 5). Although the instrument was not calibrated for cooling runs, they were nonetheless useful for a qualitative analysis of phase transformations. On the first heating run, the same R1 peak corresponding to DO3 phase, as in the case of DSC, was observed. The shapes of DSC and DTA curves are not equivalent due to the different measuring principles of the power-compensation (Perkin-Elmer DSC) and heat-flow (all DTA instruments) thermal analyzers. Thus, the DTA peaks are wider and especially their peak and end temperatures are shifted to higher temperatures than in the case of Perkin-Elmer DSC ones (Illekova et al 1992). Subsequently, borides precipitation took place (R2). The endothermic transformation (R3) indicated the melting of the sample which appeared as a partially resolved double peak. The first cooling run showed solidification of the sample, this time by two separated peaks. On the second heating run, R1 and R2 did not appear since the starting sample was no longer amorphous but crystalline and reproduced R3 peak quite well. Second cooling run fairly reproduced the solidification as well.

All thermal analyses were perfectly comparable to typical FINEMET alloys (Illekova et al 1996; Illekova 2002).

\subsection{Hysteresis loops}

Coercivity and saturation values were obtained from hysteresis loops. Coercivity can be associated to the anisotropy mean value through this equation (Herzer 1990)

$$
H_{\mathrm{C}}=p_{\mathrm{c}}\langle K\rangle / M_{\mathrm{S}},
$$

where $p_{\mathrm{c}}$ is a constant (Herzer 1995) and $\langle K\rangle$ the effective anisotropy constant. In the evolution of $H_{\mathrm{C}}$ with annealing temperature (figure 6), three different regions could be distinguished (Muraca et al 2008). 
In the first region, the material was amorphous. Thus, $\langle K\rangle$ was dominated by uniaxial magnetoelastic anisotropy: $\left\langle K_{\mathrm{u}}\right\rangle=3 / 2 \lambda_{\mathrm{s}}\langle\sigma\rangle,\langle\sigma\rangle$ being the residual stresses and $\lambda_{\mathrm{s}}$, the amorphous magnetostriction saturation constant. $\langle\sigma\rangle$ was reduced with heat treatments before first crystallization occurred. As a consequence, near $673 \mathrm{~K}$, a magnetic softening was observed. It can also be appreciated that in this first region the error was quite large and decreased with heat treatment. This was probably because of the fluctuations of $\langle\sigma\rangle$ induced during rapid quenching were reduced with annealing at higher temperatures (673 K).

When crystallites began to precipitate (region II), magnetocrystalline anisotropy started to dominate

$$
\left\langle K_{1}\right\rangle=\left(v_{\mathrm{cr}}^{2} K_{\mathrm{cr}}^{4} D^{6}\right) / A^{3},
$$

where $v_{\text {cr }}$ denotes the crystalline fraction, $K_{\text {cr }}$ the FeSi magnetocrystalline anisotropy, $D$ the grain size and $A$ the exchange constant (Herzer 1997). The material presented here has softest magnetic properties; a behaviour explained by the random anisotropy model (RAM) extended for two phases (Herzer 1997).

Table 3. Temperature parameters $[\mathrm{K}]$ and first crystallization enthalpy $\left[\mathrm{J} \mathrm{g}^{-1}\right]$ taken from DSC at 40 and $10 \mathrm{~K} \mathrm{~min}^{-1}$.

\begin{tabular}{lcc}
\hline & $40 \mathrm{~K} \mathrm{~min}^{-1}$ & $10 \mathrm{~K} \mathrm{~min}^{-1}$ \\
\hline$T_{\text {relax }}$ & $\sim 477 \cdot 5$ & - \\
$T_{\text {c,am }}$ & $594 \cdot 0$ & $595 \cdot 0$ \\
$T_{\text {onset }}$ & $811 \cdot 6$ & $792 \cdot 1$ \\
$T_{\text {peak }}$ & $834 \cdot 0$ & $811 \cdot 0$ \\
$\Delta H$ & - & $-137 \cdot 1$ \\
\hline
\end{tabular}

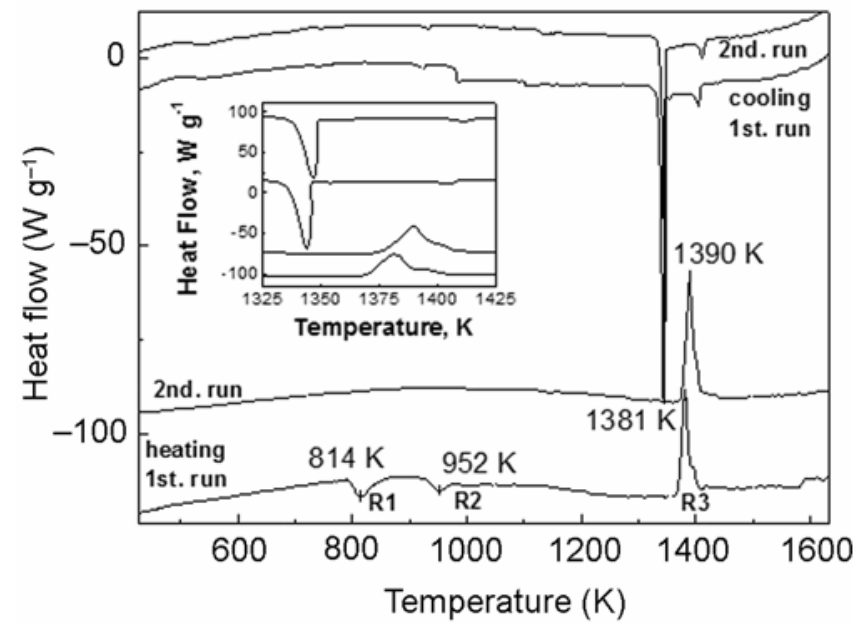

Figure 5. DTA curves of as-quenched FinCom at $10 \mathrm{~K} \mathrm{~min}^{-1}$. Peak temperatures of R1, R2 and R3 transformations are pointed out (R1: FeSi crystallization peak, R2: borides precipitation peak, R3: melting peak). Inset: an expanded view of higher temperature region. Because of transparency, orientation of $y$-axes in this figure follow orientation of $y$-axes of the DSC curves in figure 4.
Finally, in region III a magnetic hardening was seen. This hardening can be associated to the precipitation of boride compounds. Their low amount may be the reason why they were not detected in XRD, but it was still enough to act as pinning centres and reduce mobility of the Bloch walls (Hofmann et al 1992; Herzer 1997). At these annealing temperatures the material is no longer interesting from the technological point of view.

$\mu_{0} M_{\mathrm{S}}$ together with longitudinal and transversal saturation (mass) magnetizations $\left(\sigma_{\mathrm{S}}\right)$ as a function of annealing temperature are shown in figure 7 . These quantities are related to each other through the material density. No defined trend with annealing temperature could be distinguished considering error margins. The difference between longitudinal and transversal $\sigma_{\mathrm{S}}$ may be due to the shape anisotropy that favoured magnetization along the longitudinal ribbon axis. Thus, for saturating the sample

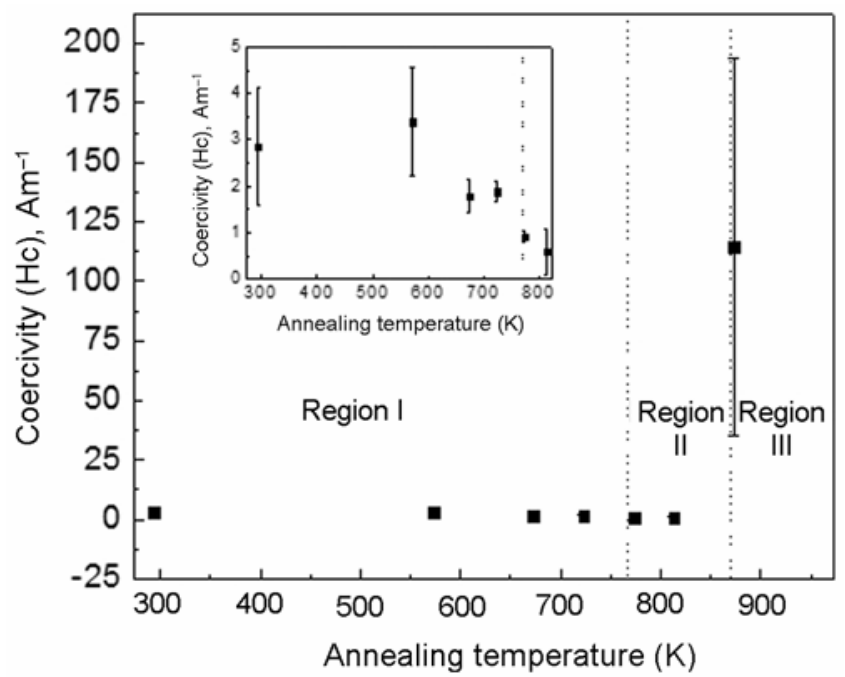

Figure 6. Coercivity $\left(H_{\mathrm{C}}\right)$ evolution with annealing temperature. Inset: an expanded view of lower temperature region.

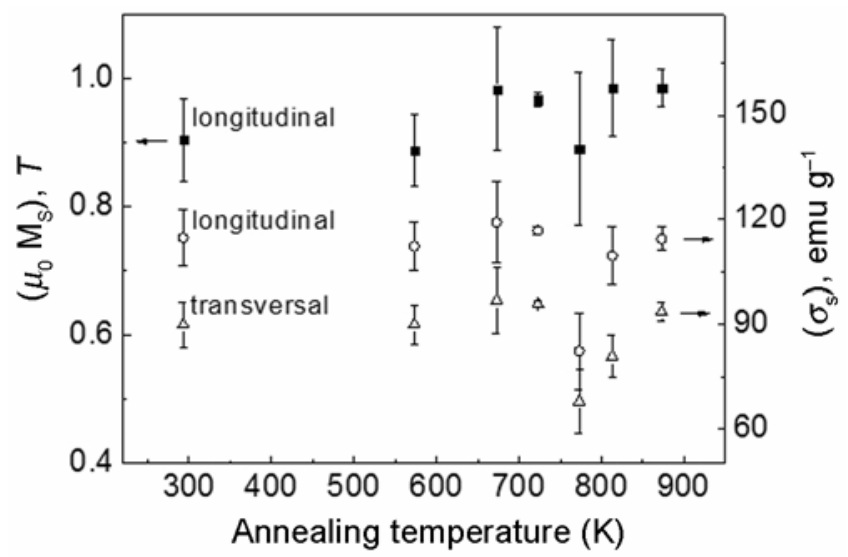

Figure 7. Longitudinal $\mu_{0} M_{\mathrm{S}}$ (left), and longitudinal and transversal $\sigma_{\mathrm{S}}$ (right) as a function of annealing temperature. 
Table 4. Cost comparison between FinCom and pure FINEMET.

\begin{tabular}{|c|c|c|c|c|c|c|c|}
\hline \multicolumn{4}{|c|}{ FinCom $\left(\mathrm{Fe}_{73 \cdot 5} \mathrm{Si}_{13} \mathrm{Nb}_{3} \mathrm{~B}_{8.5} \mathrm{Cu}_{1} \mathrm{X}_{1}\right)$} & \multicolumn{4}{|c|}{ Pure FINEMET $\left(\mathrm{Fe}_{73 \cdot 5} \mathrm{Si}_{13 \cdot 5} \mathrm{Nb}_{3} \mathrm{~B}_{9} \mathrm{Cu}_{1}\right)$} \\
\hline $\begin{array}{l}\text { Element or } \\
\text { compound }\end{array}$ & $\begin{array}{l}\text { Mass } \\
\text { (wt.\%) }\end{array}$ & $\begin{array}{c}\text { Cost } \\
\left(\mathrm{US} \$ \text { ton }^{-1}\right)\end{array}$ & $\begin{array}{c}\text { Total cost } \\
\left(\text { US\$ alloy ton }{ }^{-1}\right)\end{array}$ & Element & $\begin{array}{l}\text { Mass } \\
\text { (wt.\%) }\end{array}$ & $\begin{array}{c}\text { Cost } \\
\left(\mathrm{US} \$ \text { ton }^{-1}\right)\end{array}$ & $\begin{array}{c}\text { Total } \\
\left(\text { US\$ alloy ton }{ }^{-1}\right)\end{array}$ \\
\hline $\mathrm{FeC}$ & $70 \cdot 9$ & 145 & 10 & $\mathrm{Fe}$ & $83 \cdot 4$ & 280 & 23 \\
\hline $\mathrm{FeSi}$ & $9 \cdot 4$ & 1126 & 11 & $\mathrm{Si}$ & $7 \cdot 7$ & 16750 & 129 \\
\hline $\mathrm{FeNb}$ & 8.0 & 17258 & 138 & $\mathrm{Nb}$ & $5 \cdot 7$ & 28044 & 160 \\
\hline $\mathrm{Cu}$ & $1 \cdot 2$ & 6452 & 8 & $\mathrm{Cu}$ & $1 \cdot 3$ & 6614 & 9 \\
\hline $\mathrm{FeB}$ & $10 \cdot 5$ & 2080 & 22 & B & $2 \cdot 0$ & 5000000 & 10000 \\
\hline Total & $100 \cdot 0$ & & 189 & Total & $100 \cdot 0$ & & 10321 \\
\hline
\end{tabular}

Cost saving $($ FinCom/Pure FINEMET $)=98 \%$

in the transversal direction, a higher field should be applied.

In summary, for the commonly optimum temperature for $1 \mathrm{~h}$ annealing, i.e. $813 \mathrm{~K}$, the use of raw materials of commercial purity did not affect significantly the magnetic properties: coercivity was $\sim 0.30 \mathrm{~A} \mathrm{~m}^{-1}$ and saturation, $\sim 1.2 \mathrm{~T}$, both values are very close to those of pure FINEMET $\left(0.53 \mathrm{~A} \mathrm{~m}^{-1}\right.$ and $1.24 \mathrm{~T}$ ) (Yoshizawa et al 1988).

\subsection{Economic analysis}

In order to evaluate the convenience (or not) of using commercial purity raw materials instead of high purity ones, it is necessary to consider both physical properties and economical cost of the alloy. Thus, an economic analysis of the cost per ton of both alloys was done (FinCom and pure FINEMET) (table 4). Even though prices in the market fluctuate with time and between sellers, the reduction of costs was remarkable: $\sim 98 \%$.

The most important factor for the cost reduction was the replacement of boron for ferroboron. Moreover, it should be pointed out that special care should be taken when choosing the appropriate ferroboron. The production of ferroboron alloys is sometimes carried out by an aluminothermic reaction, leading to an aluminiumcontaining alloy. The presence of $\mathrm{Al}$ is often undesirable on the production of metallic glasses since it is easily oxidized and the resulting oxides interfere with amorphization (Moya 1999). Thus, ferroboron produced by the carbothermic method should be used instead (Fichte et al 1986).

\section{Conclusions}

FINEMET prepared with commercial raw materials demonstrated to have structural, calorimetric and magnetic properties very close to those of pure FINEMET. Coercivity and saturation, two key parameters for the material's performance, of the nanocrystalline samples $(16 \mathrm{~nm}$,
$\mathrm{Fe}_{80.5} \mathrm{Si}_{19.5}$ grains embedded in a remnant amorphous matrix) resulted in $0.30 \mathrm{~A} \mathrm{~m}^{-1}$ and $1.2 \mathrm{~T}$, respectively. It was shown that the reduction in costs when using commercial raw materials was outstanding (almost 98\%), making these alloys very attractive for applications in the industry and research laboratories as well. These results may be important not only for the production of FINEMETs, but for other soft and hard magnetic materials with similar constitutive elements as well, such as FeSiB alloys, NANOPERMs, HITPERMs and $\mathrm{NdFeB}$.

\section{References}

Ayers J D, Harris V G, Sprague J A, Elam W T and Jones H N 1997 Nanostruct. Mater. 9391

Brand R A 1987 Normos Program, Internal Report, Angewandte Physik, Universität Duisburg

Choi Y G, Lee K A and Lee K S 2007 Met. Mater. Int. 13269

Crisan O, Le Breton J M and Filoti G 2003 Sens. Actuators A106 246

Fichte R, Breuer F, Hähn R and Retelsdorf H J 1986 Method of making ferroboron and ferroborosilicon alloys and the alloys made by this method, United States Patent, Patent number: $4,569,69)$

Herzer G 1990 IEEE Trans. Magn. 261397

Herzer G 1995 Scr. Metall. Mater. 331741

Herzer G 1997 in Handbook of magnetic materials (ed.) K H J Buschow (Amsterdam: Elsevier) Vol. 10, pp. 415, 422

Herzer G, Vazquez M, Knobel M, Zhukov A, Reininger T, Davies H A, Grössinger R and Sanchez J L 2005 J. Magn. Magn. Mater. 294252

Hofmann B, Reininger T and Kronmüller H 1992 Phys. Status Solidi A134 247

Illekova E 2002 Thermochim. Acta 38747

Illekova E, Aba B and Kuhnast F A 1992 Thermochim. Acta 195, 195, 211

Illekova E, Czomorova K, Kuhnast F A and Fiorani J M 1996 Mater. Sci. Eng. A205 166

Kim S U, Kim K H and Koo Y M 2004 J. Alloys Compd. 368 357

Klug H P and Alexander L E 1954 X-ray diffraction procedures (New York: Wiley) p. 586 
Moya J A 1999 Materiales magnéticos blandos de estructura nanométrica, PhD thesis, Universidad de Buenos Aires, Buenos Aires, Argentina

Moya J A, Cremaschi V J and Sirkin H 2007 Phys. B389 159

Muraca D, Cremaschi V, Moya J and Sirkin H 2008 J. Magn. Magn. Mater. 3201639

Muraca D, Silveyra J, Pagnola M and Cremaschi V 2009 J. Magn. Magn. Mater. 3213640

Prabhu D, Ganesan K, Narayanasamy A, Chattopadhyay K and Ponpandian N 2007 Mater. Sci. Eng. A449-451 452
Rixecker G, Schaaf P and Gonser U 1992 J. Phys. Condens. Matter 410295

Rixecker G, Schaaf P and Gonser U 1993 Phys. Status Solidi A139 309

Silveyra J M, Moya J A, Cremaschi V J, Janickovic D and Svec P 2009 Hyperfine Interact. DOI: 10.1007/s10751-009-0116-4

Tamoria M R, Carpenter E E, Miller M M, Claassen J H, Das B N, Stroud R M, Kurihara L K, Everett R K, Willard M A, Hsiao A C, McHenry M E and Harris V G 2001 IEEE Trans. Magn. 372264

Yoshizawa Y, Oguma S and Yamauchi K 1988 J. Appl. Phys. 646044 